\title{
Enhancing Metaphor and Metonymy Comprehension in Children with High-Functioning Autism Spectrum Disorder
}

\author{
Sergio Melogno ${ }^{1 *}$, Maria Antonietta Pinto ${ }^{2}$ \\ ${ }^{1}$ Department of Paediatrics and Neuropsychiatry, University of Rome "La Sapienza", Rome, Italy \\ 2Department of Developmental and Social Psychology, University of Rome "La Sapienza", Rome, Italy \\ Email: *sergio.melogno@uniroma1.it, mariantonietta.pinto@uniroma1.it
}

Received 10 June 2014; revised 5 July 2014; accepted 29 July 2014

Copyright (C) 2014 by authors and Scientific Research Publishing Inc.

This work is licensed under the Creative Commons Attribution International License (CC BY).

http://creativecommons.org/licenses/by/4.0/

(c) (i) Open Access

\section{Abstract}

This article addresses how to enhance metaphor and metonymy comprehension in children with high-functioning autism spectrum disorder (HF-ASD), who are known to have difficulties with figurative language. After considering some major issues on typical development and in HF-ASD, and some studies on treatment in this specific domain, the authors describe an intervention methodology that can be used in schools and clinics. This methodology is based on two main points: 1) the explicit teaching of strategies for understanding metaphors and 2) activities for enhancing the abstraction of semantic features in metaphors and metonymies. The authors show how these devices can make complex processes such as figurative language comprehension more concrete for children with HF-ASD.

\section{Keywords}

\section{Autism Spectrum Disorder, High-Functioning, Metaphor, Metonymy, Intervention Strategies}

\section{Introduction}

Matthew (a pseudonym) is a 9-year-old child with high-functioning autism spectrum disorder (HF-ASD). His full scale IQ, as measured by a well-known intelligence test (Wechsler, 2004) is 98; however, in spite of this overall adequate intellectual level and fluent language, Matthew exhibits all the typical interactional and com-

${ }^{*}$ Corresponding author.

How to cite this paper: Melogno, S., \& Pinto, M. A. (2014). Enhancing Metaphor and Metonymy Comprehension in Children with High-Functioning Autism Spectrum Disorder. Psychology, 5, 1375-1383.

http://dx.doi.org/10.4236/psych.2014.511148 
municative difficulties associated with autistic children. His eye contact is anomalous, and he makes little use of and rarely attempts to integrate the usual means of communication (i.e., social smile and gestures). He shows some repetitive behaviors, and his encyclopedic knowledge of the human body, and biology in general, often monopolizes his conversations.

Sometimes, he resorts to stereotypical phrases. For instance, when he gets in trouble for some reason, he uses the phrase, "It's my brain that tells it to me!" Matthew started using this phrase after he had heard it from a DVD about the brain. From that moment on, he began overusing it.

Social cognition is a weak point in Matthew's cognitive profile. He has difficulty drawing information from perceptual cues such as the eyes and prosody. In general, he gets in trouble when he has to infer what others are thinking and/or establish empathic relationships with them.

Understanding nonliteral language is also difficult for Matthew. When faced with metaphorical usages, he usually reacts in three different ways. In some cases, he firmly refuses a metaphorical utterance saying that "it is not true," or that "it's false." For instance, he cannot accept sentences such as, "Skyscrapers are a city's giraffes" because he limits himself to a literal interpretation: Skyscrapers are buildings, whereas giraffes are animals. The only plausible explanation for a sentence such as, "A babysitter is a cup of chocolate" is of a metonymic type: "A babysitter is fond of chocolate, so, of course, she drinks cups of chocolate." In other cases, Matthew is apparently attracted by the sound of words and gets lost in rhymes. For instance, for the metaphor "Butterflies are rainbows," Matthew says, "rain on my brain, in a train...."

In everyday life, Matthew's parents and teachers report these difficulties, and they agree that the child often reacts with confusion when people use metaphors or other figures of speech such as metonymies, hyperboles, or ordinary idioms. One day, at school, the teacher addressed a child using the idiom, "you have your head in the clouds" and Matthew did not understand. He got up and started staring at his classmate's neck. When the teacher addressed a girl who was chatting using the expression, "I am talking to the red T-shirt" (a metonymic phrase), Matthew reacted as if the teacher had presented a riddle. Matthew's parents know that if they say, "Stop a minute" (a hyperbole), the child will stop and then restart what he was doing after exactly sixty seconds. A child with the same IQ level as Matthew—but without ASD—would never react the same way.

Matthew can come to understand these nonliteral expressions if someone teaches him. This characteristic has a high adaptive value since everyday language is very rich in nonliteral phrases.

The aim of the present work is to describe a program of activities that can be implemented with children having difficulties similar to those exhibited by Matthew, with a special focus on metaphors and metonymies. These suggestions can prove helpful for children with High-functioning ASD (including autism, Asperger's syndrome, and pervasive developmental disorder not otherwise specified, based on DSM IV, American Psychiatric Association, 2000). As is well known, high-functioning children are defined by having an IQ within norms. The program of activities that will be described can also apply to children with linguistic and communicative difficulties of a pragmatic type (DSM 5, American Psychiatric Association, 2013).

\section{Metaphor and Metonymy: What Is It?}

Metaphors and metonymies are generally considered the two major figures of speech. Any metaphor, even the simplest, is composed of two parts— the subject $(\mathrm{X})$, and the predicate $(\mathrm{Y})$ - and takes the typical form of " $\mathrm{X}$ is Y." For instance, when we say, "John is a rock," John is the subject, and rock is the predicate. As these two words pertain to completely different domains - that of human beings and that of inanimate things - we may wonder on what grounds have they been associated so as to constitute an ordinary expression. This implies that there must be a common ground, where some features of the subject share similarities with some characteristics of the predicate. In the above case, the common feature shared by both John and the rock can be seen in being hard. Beyond possible similarities between the subject and the predicate of a metaphor, there still remains a discrepancy between them, which explains that surprise effect that metaphors typically create.

Metonymy is also a figure of speech in which a thing or concept is not called by its own name but by the name of something intimately associated with that thing or concept. For instance, when we say, "He is having a glass" instead of "He is drinking something" (wine, water, juice, etc., in terms of a given type of content of the glass), we are making a sort of mental shortcut that directly points to the container instead of indicating the content. Metonymy can create other types of shortcuts, such as cause/effect, instrument/goal, and part/whole.

Metaphors and metonymies are sometimes erroneously treated as idioms. Idioms, in fact, are a subcategory of 
figurative language having only one meaning conventionalized by a given linguistic community (Gibbs, 1994). An example is the expression used by Matthew's teacher: "You have your head in the clouds". Moreover, it is not always possible to reconstruct this conventionalized meaning from the single words that compose the idiom, and, as a consequence, we directly retrieve this meaning from memory, if we have previously acquired it.

\section{Metaphor Comprehension}

Understanding metaphors and metonymies poses particular problems to children, and developmental psychologists have extensively studied forms and levels of these difficulties for decades, mainly focusing on metaphors.

Physico-psychological metaphors that link words pertaining to two different semantic domains - the physical and the psychological—as in the aforementioned association "John/rock," generate greater difficulties in processing, similar to the "babysitter" example in Matthew's case (Cicone, Gardner, \& Winner, 1981).

In a classical study by Winner, Rosentiel, \& Gardner (1976), in which the authors presented physico-psychological metaphors such as "After many years of working at the jail, the prison guard had become a hard rock that could not be moved," the developmental sequence was found to be very articulated and long. Before age six, responses categorized as magical, metonymical, and sometimes primitive metaphoric were common. Some children explained that the guard had been transformed into a rock by a divine or unearthly entity: "The king had a magic rock, and he turned the guard into another rock" (magic interpretation). Other interpretations included, "The guard worked in a prison with hard rock walls" or "he used to stay on a rock" (metonymic interpretation), where meanings were put one beside the other, on spatial grounds. An example of a primitive metaphoric response was, "The guard had muscles as hard as rocks," which attests to an initial search for common ground between the two terms of the metaphor guard and rock. This type of analogical reasoning is central to metaphors, although it is still based on concrete grounds. Between the ages of seven and ten years, children begin to link these two terms on psychological grounds and explain that the guard was "hard because he did not care about the feelings of the prisoners.” This type of explanation was categorized by the authors as a genuine metaphoric response. In sum, the distinction between primitive and genuine metaphoric responses is based on the fact that the former entirely focus on concrete features whereas the latter focus on more abstract features, in this case on psychological traits.

Subsequent studies highlighted that, children as young as five are able to adequately process physico-psychological metaphors when these are presented in multiple choice tasks (Waggoner \& Palermo, 1989). At the age of five, children are also able to verbally explain sensorial metaphors, which link two objects of the same physical domain (e.g., "The sun is an orange," "Butterflies are rainbows," "The river is a snake" or, in Matthew's case, "Skyscrapers are city giraffes" (Siltanen, 1986; Gentner, 1988). At this age, children are already able to identify some characteristics shared by the two terms in the metaphor (e.g., shape, color, and movement) and to make them explicit.

In everyday conversation, two speakers may focus on various types of interpretations according to the context of their conversation, implicitly negotiating their intended meaning. In other words, metaphor understanding partially calls for the capability to appropriately read the others' mental states. The relevance of this capability might at least partly explain the delays and deficits that have been found in children with ASD.

\section{Metaphor and Metonymy Understanding in Children with ASD}

Many studies indicate that children with ASD may have difficulty understanding metaphors (Happé, 1993, 1995; Norbury, 2005; Rundlabd \& Annaz, 2010; Melogno, D’Ardia, Pinto, \& Levi, 2012). The first experimental studies were conducted in the early 1990s, in the pioneering research of Happé (Happé, 1993, 1995). According to Happé, understanding metaphors requires the capability to infer a speaker's communicative intentions and, more generally, to attribute mental states to the speaker, a capability referred to as theory of mind (Baron-Cohen, Leslie, \& Frith, 1985). For instance, when someone hears the metaphorical sentence "John is a rock", he/she must attribute the speaker that he/she is actually meaning that "John is like a rock" and not that "John is really a rock".

While some studies apparently supported explanations based on theory of mind (Dennis, Lazenby, \& Lockyer, 2001; Martin \& Donald, 2004), further studies explored other types of explanations. For example, Norbury (2005) showed that theory of mind is a necessary condition for metaphor comprehension but not the only one, because metaphor comprehension draws upon specific lexical notions and extralinguistic knowledge. In the 
aforementioned example "John is a rock", the feature "hardness" that is implicit in the term "rock" may be intended on a concrete, sensorial plane or on a psychological plane that calls for more abstractive cognitive processes.

This is where the distinction between sensorial and physico-psychological metaphors can shed light on semantic difficulties in ASD children. Understanding sensorial metaphors can be based on concrete grounds, whereas understanding physico-psychological metaphors requires to appropriately combine concrete and psychological features. The distinction between these two types of metaphors has rarely been addressed in studies on children with ASD (Melogno et al., 2012), where metaphors of both types were administered without a clear specification of the degree of complexity of each of them. For instance, in Norbury's study (2005), tasks included such metaphors as "Father is a volcano" (a typical example of a physico-psychological metaphor) together with other metaphors such as "Hair is spaghetti" or "The tree is a tower" (typical examples of sensorial metaphors). Future research will have to explore how children with ASD’ performances in metaphor comprehension may vary as a function of the complexity of different types of metaphors.

Problems with figurative language in individuals with ASD are not limited to metaphors (McKay \& Shaw, 2004); these individuals may also have difficulty comprehending metonymies and other figures of speech (for a review on a developmental perspective about metaphor and metonymy, (see Melogno, Pinto, \& Levi, 2012). Rundblad \& Annaz (2010), studying developmental trajectories of metaphor and metonymy, concluded that children with autism from 5 to 11 years presented impaired performance in metaphor comprehension and delayed performance with regard to metonymy.

\section{Can Metaphor Comprehension Be Enhanced in Children with HF-ASD?}

Experimental studies about interventions for enhancing metaphor comprehension in children with HF-ASD are currently scarce, but those available offer stimulating ideas about the type of activities that can be implemented, either in a school context or in clinical settings.

We will mention three interesting studies focused on intervention: one by Whyte, Nelson, \& Khan (2013), who attempted to teach idioms to children with HF-ASD, and two more (Mashal \& Kasirer, 2011; Persicke, Tarbox, Ranick, \& St. Clair, 2012) who attempted to enhance metaphor comprehension in children with ASD.

Ten children participated in the first study (Whyte et al., 2013), where an operator introduced a topic in a circle time moment. Idioms were embedded in a paragraph that the operator presented to the group; the children had to express the way they intended these idioms and then they were invited to work individually on a worksheet related to each idiom. Children had to color a clipart picture representing the nonliteral meaning of the idiom, they then had to write the meaning that emerged from previous discussion within the group, and finally, they had to draw this same meaning. Furthermore, children were asked to think about new possible contexts where the idiom could be plausibly inserted. The staff members discussed the content of the worksheets with each child so that the discussion itself took the form of an interactive tool.

Mashal \& Kasirer (2011) used thinking maps as an instrument that could enable children to visualize the semantic relations between subject and predicate in metaphors. Thus, thinking maps provided a visual-verbal device for improving metaphoric understanding, as illustrated in the example below. For instance, for the metaphor "Train of thought," children had to write the two terms train and thought in two central bubbles and their semantic associations in the surrounding bubbles. In order to grasp the relevant interpretation of the metaphor, the researcher instructed children to write the appropriate associations between train and thought. In this sample metaphor, a possible link could be continuity or connected thoughts. The correct option required the children to exclude irrelevant associations between the first term and other words (i.e., train as associated with cars or with engine) and between the second term and other words (i.e., thought as associated with brain or with in the head). This practice was meant to stimulate children to generate a wide range of semantic associations that they had to elaborate by switching from one to another until they found the appropriate link.

The third study, by Persicke \& collaborators (2012), was based on the Relational Frame Theory (RFT), which treats the various ways an individual can relate one thing to another as relational frames (for a description, see Hayes, Barnes-Holmes, \& Roche, 2001; Rehfeldt \& Barnes-Holmes, 2009). Relating is conceptualized as a generalized operant behavior, in Skinner's perspective (Skinner, 1957), learned via a history of multiple exemplar training events. Concerning metaphor comprehension, this theory predicts that three relational frames are particularly relevant to metaphorical language: coordination, hierarchy, and distinction (Stewart \& Barnes-Holmes, 2001a, 2001b). 
Relating in terms of coordination is the behavior of relating two or more stimuli as similar or the same. For example, one might relate the spoken word apple and an actual apple as similar. Relating in terms of distinction is the behavior of relating one stimulus as different from another. For example, one might relate an apple as different from a rock. Relating in terms of hierarchy is the behavior of relating one stimulus to other stimuli that "belong to it." For example, the word mammal is related to the words dog, dolphin, and whale in the sense that all three are examples of mammals. The concept that a thing or stimulus has "features" also involves hierarchical relating. For example, the stimulus apple can be related to fruit, you can eat it, and grows on trees, in the sense that all three are features of an apple.

For understanding a metaphorical sentence such as "this apple is candy," we first relate the first term (the subject, see above) to its properties; then, we relate the second term (the predicate, see above) to its properties as well (hierarchy relation). By comparing the properties of the first and second terms, we find a property than can be shared by both terms, which represents a coordination relation. To this end, we must discard properties that the two terms do not share (distinction relation). Persicke \& Collaborators (2012) operationalized these processes into a series of devices for enhancing metaphor reasoning in children with ASD via multiple exemplar training. For example, they used stories containing metaphors and asked the participants (three children with ASD) to list the features that characterized each term of the metaphors in worksheets and then to draw a line connecting the shared feature.

\section{Teaching Strategies for Understanding Metaphors and Metonymies}

As anticipated, children like Matthew, who are high functioning and with fluent language abilities, can be taught the meaning of some figurative language usages. We will illustrate in this section how the comprehension processes of metaphor and metonymy can be taught in an explicit manner. One of the most typical reactions of Matthew to these kinds of figures of speech is the refusal of their very existence.

Concerning metaphors, we will explain some strategies we used to teach Matthew how to overcome this obstacle. By "strategy," we mean what the literature on interventions on oral and written text comprehension defines as a mental action to which the individual intentionally resorts during his/her comprehension process (Shanahan, Callison, Carriere, Duke, Pearson, Schatschneider, \& Torgesen, 2010). To facilitate metaphor understanding, two strategies can be taught to Matthew: the heuristic of " $\mathrm{X}$ is like $\mathrm{Y}$," and the comparative strategy. Although interconnected, these two strategies can be seen as two steps of the comprehension process. For example, in the case of a metaphor of the type " $\mathrm{X}$ is $\mathrm{Y}$," the former strategy introduces the phrase "is like" between the two terms, which transforms an impossible identity - that Matthew would refuse on literal grounds-into a plausible comparison. The aim is to help Matthew overcome the obstacle posed by the metaphor, where a speaker says that something "is something else" but actually means that something "is like something else." In this way, it is no longer necessary to infer the intention of saying something metaphorically since the intention is made explicit. At this point, a concrete comparison can be considered and analyzed in order to find some common characteristics between the terms " $\mathrm{X}$ " and " $\mathrm{Y}$ " that are likely to explain the meaning of the metaphor.

A given strategy can be taught as a single device (i.e., single strategy approach) or together with other strategies (i.e., multiple strategy approach) (Shanahan et al., 2010). With Matthew, the second approach can be adopted and its implementation is based on four steps: 1) the adult first explains the strategies; 2) the adult models the strategies; 3 ) the adult and child both practice the strategies in shared activities; 4) the child practices the strategies in some guided individual activity. As an example of Step 3, we will report on a joint adult-child practice, based on a story that contained a certain metaphor.

Camilla is a girl who never wanted to go to school; her mother used to awake her every morning, but the girl continued to stay in bed; one day her mother angrily shouted at her: "I know that you are awake. If you don't hurry up you will be late at school ... Camilla is a snail.”

The adult and the child start to apply the heuristics of X is Y: "Camilla is not a snail. She is a little girl. Let's try our first strategy; Camilla is not really a snail but, in some way, she is like it.” Then, the adult and Matthew start applying the comparative strategy by creating a thinking map (Mashal \& Kasirer, 2011) on a sheet of paper. In the right part of this sheet, the adult draws a bubble and writes "snail" and invites Matthew to make a list of all the features of the snail. Matthew says, "a mollusk, an animal, slow, slime," and "it comes out when it rains a lot." Each of these features is written in its own bubble and all are connected to each other. Additionally, an image of a little girl is drawn on the left side of the sheet. 
The adult and child alternatively focus on the images and the words present in the left and in the right side of the sheet and this shared activity stimulates the child to establish suitable connections between "X" and "Y." In particular, the child is induced to progressively discard those features that prove to be irrelevant to the comparison (i.e., mollusk, animal, slime, goes out when there is a lot of humidity) and to maintain the features slow and small, which can be realistically applied to a little girl. Eventually, the adult invites the child to recall the original context where the metaphor was uttered by the mother for reconstructing what she could have in mind when she said, "Camilla is a snail". In this case, the only possibility left to the child is the feature slow.

The adult then introduces an explicit metalinguistic comment on the original metaphor and says that the word snail stands for a salient characteristic of the snail itself, namely, its slowness. In addition, the adult stresses the difference between "saying" and "meaning". We can say that a girl or a boy or X is a snail but, actually, we mean that they are slow.

\section{Visual Aids}

To help children with ASD like Matthew become as autonomous as possible in handling metaphors, three types of visual aids were provided, that is, three types of cards that visualize as many aspects of the metaphor comprehension process.

The first aspect of this process concerns the difference between "saying" and "meaning". In the type of cards that illustrates this aspect, there are two bubbles coming out from the head of a character: the thought in the bubble on the left side is expressed by the words "he/she means", whereas the thought on the right side is expressed by the words "he/she says" (Figure 1).

The second aspect of the metaphor comprehension process is the abovementioned, "heuristics of X is like Y". This type of card presents two characters who are talking to each other; the character on the left side says, " $\mathrm{X}$ is $\mathrm{Y}$ ”, and the one on the right side thinks, "X is like Y" (Figure 2).

The third type of card illustrates what we called the comparative strategy and can be visualized in a thinking map like the one appearing in Figure 3 that reports the physico-psychological metaphor, "That man is a clock". It can be seen from the image, only two features can be shared by the terms man and clock as they are both interpretable in a physical and a psychological sense: reliable and precise. As such, these features are good candidates for an appropriate interpretation of the metaphor.

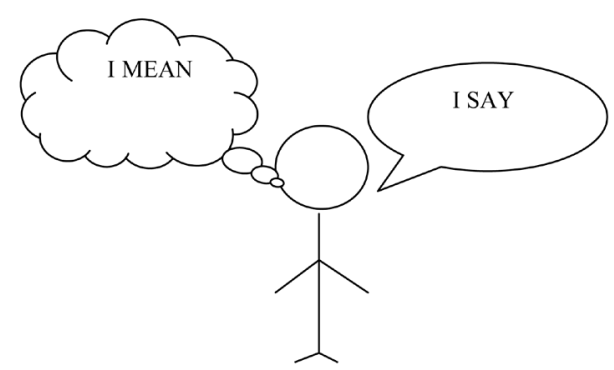

Figure 1. Card no. 1: Illustrating the meaning/ saying distinction.
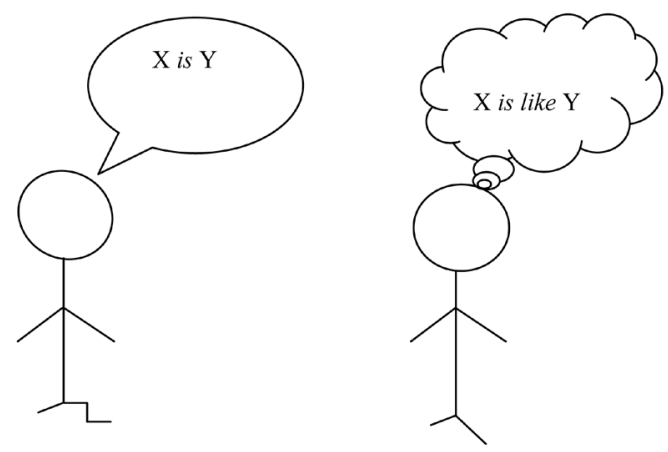

Figure 2. Card no. 2: visualizing the heuristics of “... is like”. 


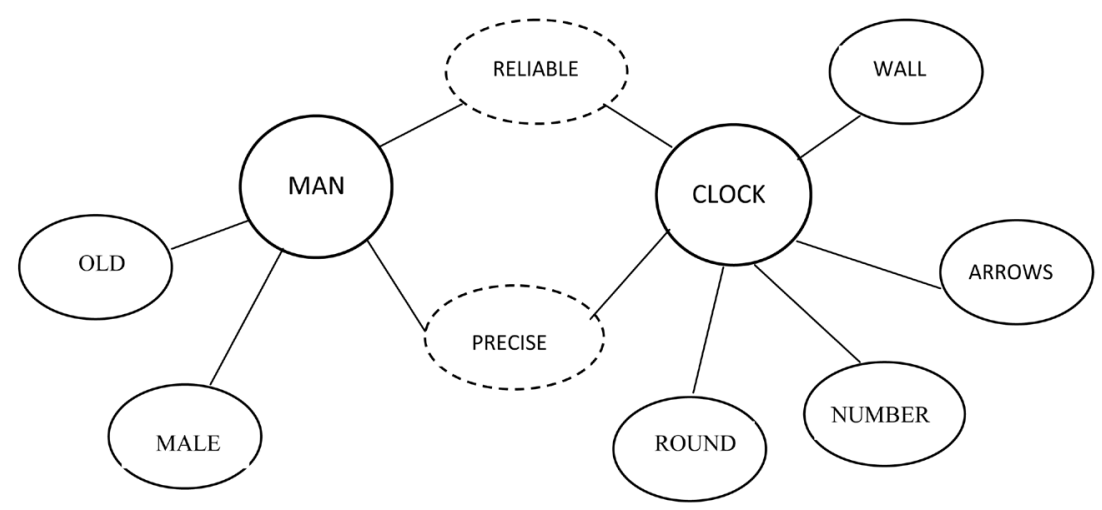

Figure 3. Thinking map.

\section{Enhancing Abstractive Processes}

Both sensorial and physico-psychological metaphors are proposed to Matthew, and in both cases, the two strategies just described (the " $\mathrm{X}$ is like $\mathrm{Y}$ " and the comparative heuristic) are suitable. However, for the physicopsychological metaphors, which associate physical and human characteristics, the process of abstracting semantic features is more demanding. One of the reasons is that this type of metaphor can also be intended in concrete terms, as in the case of the slowness of the snail, in Camilla's example. However, when we shift from the physical to the psychological level, as in the prison guard example, the feature shared by guard and rock (hardness) undergoes a semantic transformation from a concrete to an abstract plane. As a consequence, the hardness of the person has nothing more to share with the hardness of the rock.

To strengthen Matthew's capability of abstracting semantic features, two more activities have been proposed. The first type of activity was inspired by classical studies on spontaneous production of metaphors in normally developing preschoolers (Winner, 1979, 1988; Elbers, 1988). These children were often found to rename objects in a seemingly metaphorical manner, although they possessed the corresponding literal term. Matthew was presented various objects and pictures of objects, or movies representing static objects or objects in motion (e.g., a shell, a stop signal, an apple, ocean waves, etc.). The child is requested to rename things and to justify these changes. For instance, Matthew would rename the shell as "a cup of water" on the basis of their common shape and function. In a classroom or in a small group in a clinical setting, this activity can be conducted with children by asking them to "rename themselves" and to "rename the others" (Engel \& Glick, 1982), for instance, "if John was a fruit, he would be a small berry" and "if Peter was an animal, he would be a panther." These comparisons are meant to encourage children to shift from a physical to a psychological and more abstract plane.

Another activity that stimulated the child to actively abstract and compare features between the terms contained in metaphors was based on a set of images representing various types of objects or events on the right side of a sheet of paper. The child was asked to label them and express his encyclopedic knowledge about these pictures. On the left side of the sheet, one image was presented that could be the potential subject of a metaphor. The adult and the child alternatively verbalized the relation between this isolated image $(\mathrm{X})$ and the images on the right side of the sheet (Y1, Y2, Y3, etc.), by saying: "X is like... (Y1 or Y2; Figure 4)". See Figure 4.

Matthew was then requested to justify his personal choice (e.g., "that child $(\mathrm{X})$ is a tortoise $\left(\mathrm{Y}_{\mathrm{n}}\right)$ ") and to find an appropriate context where this association could be plausibly used. For instance, if he matched child with tortoise, he might say that this happened "in the morning when he/she has to get dressed", or "when the teacher poses a question and that child is very slow in answering".

The adult discussed all of these contextualized uses to help make Matthew more aware of the fact that the same word can mean different things according to the context.

\section{Enhancing Metonymic Comprehension}

As previously noted, metonymic expressions are also very frequent in everyday communication. This consideration led us to plan a part of the intervention specifically devoted to enhancing the understanding of this type of expression - where words are substituted by other words on the basis of spatial, temporal, or cause-effect relations, and not on the basis of similarity, as in metaphors. 


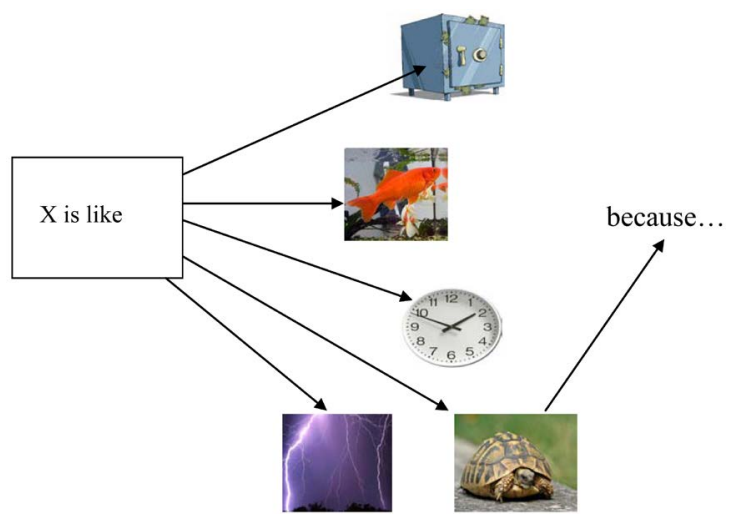

Figure 4. Matching subjects and predicates.

The activity implemented to this end was based on short videos presenting social situations. For instance, a video showed a teacher blaming a pupil wearing a red T-shirt, using the following expression: "the red T-shirt in the background, please shut up!” The adult led Matthew through a step-by-step analysis of the contextual usage of the metonymy T-shirt: "Does anyone wear a T-shirt in the classroom?"; "What was the girl with the red T-shirt doing? (She was chatting and disturbing the class)"; "What did the teacher mean, then?" In this way, Matthew could be helped in reconstructing the relations between the parts (the T-shirt) and the whole (the pupil wearing it and behaving badly).

\section{Conclusion}

In this article, we outlined some intervention activities that addressed specific difficulties in understanding metaphorical and metonymical usages in children with high-functioning ASD. We presented the case of a 9-yearold child - Matthew — whose reactions to this type of expressions exemplified the kind of difficulties that this population experiences when facing these expressions in everyday communication. To help these children overcome their tendency towards literal interpretations and their trouble in reconstructing the communicative intentions underlying metaphors, two main types of intervention activities were implemented. The first consisted of teaching strategies for transforming metaphors into explicit comparisons between terms. This device can make the understanding process more concrete as well as bring to light the speaker's intention when talking metaphorically. Then, the children were taught how to perform the comparisons by means of thinking maps.

The second type of intervention addressed the ability to abstract semantic features in metaphorical and metonymical expressions. To this end, various tasks were devised, typically renaming tasks that required analysis of semantic differences and similarities between objects and events.

These interventions, while making ASD children's cognitive processes more concrete, can also improve their communicative competencies.

\section{References}

American Psychiatric Association (2000). Diagnostic and Statistical Manual of Mental Disorders (4th ed.). Washington DC: Author.

American Psychiatric Association (2013). Diagnostic and Statistical Manual of Mental Disorders (5 ${ }^{\text {th }}$ ed.). Arlington, VA: American Psychiatric Publishing.

Baron-Cohen, S., Leslie, A., \& Frith, U. (1985). Does the Autistic Child Have a “Theory of Mind”? Cognition, $21,37-46$. http://dx.doi.org/10.1016/0010-0277(85)90022-8

Dennis, M., Lazenby, A., \& Lockyer, L. (2001). Inferential Language in High-Functioning Children with Autism. Journal of Autism and Developmental Disorders, 31, 47-54. http://dx.doi.org/10.1023/A:1005661613288

Elbers, L. (1988). New Names for Old Words: Related Aspects of Children's Metaphors and Compounds. Journal of Child Language, 15, 591-617. http://dx.doi.org/10.1017/S0305000900012587

Engel, S., \& Glick, J. (1982). “Did You Ever Buy Two Watermelons?” A Study in Children’s Use of Metaphors. New York: Graduate Center City University of New York. 
Gentner, D. (1988). Metaphor as Structure-Mapping: The Relational Shift. Child Development, 59, 47-59. http://dx.doi.org/10.2307/1130388

Gibbs, R. W. (1994). The Poetics of Mind. Figurative Thought, Language, and Understanding. Cambridge: Cambridge University Press.

Happé, F. (1993). Communicative Competence and Theory of Mind in Autism: A Test of Relevance Theory. Cognition, 48, 101-119. http://dx.doi.org/10.1016/0010-0277(93)90026-R

Happé, F. (1995). Understanding Minds and Metaphors: Insight from the Study of Figurative Language in Autism. Metaphor and Symbolic Activity, 10, 275-295. http://dx.doi.org/10.1207/s15327868ms1004_3

Hayes, S. C., Barnes-Holmes, D., \& Roche, B. (2001). Relational Frame Theory: A Post-Skinnerian Account of Human Language and Cognition. New York: Plenum Press.

Martin, I., \& McDonald, S. (2004). An Exploration of Causes of Non-Literal Problems in Individuals with Asperger Syndrome. Journal of Autism and Developmental Disorders, 34, 311-328. http://dx.doi.org/10.1023/B:JADD.0000029553.52889.15

Mashal, N., \& Kasirer, A. (2011). Thinking Maps Enhance Metaphoric Competence in Children with Autism and Learning Disabilities. Research in Developmental Disabilities, 32, 2045-2054. http://dx.doi.org/10.1016/j.ridd.2011.08.012

McKay, G., \& Shaw, A. (2004). A Comparative Study of Figurative Language in Children with Autistic Spectrum Disorders. Child Language Teaching and Therapy, 20, 13-32. http://dx.doi.org/10.1191/0265659004ct261oa

Melogno, S., D’Ardia, C., Pinto, M. A., \& Levi, G. (2012). Explaining Metaphors in High-Functioning Autism Spectrum Disorder Children: A Brief Report. Research in Autism Spectrum Disorders, 6, 683-689.

http://dx.doi.org/10.1016/j.rasd.2011.09.005

Melogno, S., Pinto, M. A., \& Levi, G. (2012). Metaphor and Metonymy Comprehension in ASD Children: A Critical Review from a Developmental Perspective. Research in Autism Spectrum Disorders, 6, 1289-1296. http://dx.doi.org/10.1016/j.rasd.2012.04.004

Norbury, C. F. (2005). The Relationship between Theory of Mind and Metaphor: Evidence from Children with Language Impairment and Autistic Spectrum Disorder. British Journal of Developmental Psychology, 23, 383-399. http://dx.doi.org/10.1348/026151005X26732

Persicke, A., Tarbox, J., Ranick, J., \& St. Clair, M. (2012). Establishing Metaphorical Reasoning in Children with Autism. Research in Autism Spectrum Disorders, 6, 913-920. http://dx.doi.org/10.1016/j.rasd.2011.12.007

Rehfeldt, R. A., \& Barnes-Holmes, Y. (2009). Derived Relational Responding: Applications for Learners with Autism and Other Developmental Disabilities. Oakland, CA: New Harbinger Publications, Inc.

Rundblad, G., \& Annaz, D. (2010). The Atypical Development of Metaphor and Metonymy Comprehension in Children with Autism. Autism, 14, 29-47. http://dx.doi.org/10.1177/1362361309340667

Shanahan, T., Callison, K., Carriere, C., Duke, N. K., Pearson, P. D., Schatschneider, C., \& Torgesen, J. (2010). Improving Reading Comprehension in Kindergarten trough 3rd Grade: IES Practice Guide, NCEE 2010-4038. Washington DC: National Center for Education Evaluation and Regional Assistance, Institute of Education Sciences, US Department of Education.

Siltanen, S. A. (1986). Butterflies Are Rainbows? A Developmental Investigation of Metaphor Comprehension. Communication Education, 35, 1-12. http://dx.doi.org/10.1080/03634528609388314

Skinner, B. S. (1957). Verbal Behaviour. New York: Appleton-Century-Crofts.

Stewart, I., \& Barnes-Holmes, D. (2001a). Relations among Relations: Analogies, Metaphors, and Stories. In S. C. Hayes, D. Barnes-Holmes, \& B. Roche (Eds.), Relational Frame Theory: A Post-Skinnerian Account of Human Language and Cognition (pp. 73-86). New York: Kluwer Academy.

Stewart, I., \& Barnes-Holmes, D. (2001b). Understanding Metaphor: A Relational Frame Perspective. The Behavior Analyst, 24, 191-199.

Waggoner, J. E., \& Palermo, D. S. (1989). Betty Is a Bouncing Bubble: Children’s Comprehension of Emotion-Descriptive Metaphors. Developmental Psychology, 25, 152-163. http://dx.doi.org/10.1037/0012-1649.25.1.152

Wechsler, D. (2004). The Wechsler Intelligence Scale for Children (4th ed.). London: Pearson Assessment.

Whyte, E. M., Nelson, K. E., \& Khan, K. S. (2013). Learning of Idiomatic Language Expressions in a Group Intervention for Children with Autism. Autism, 17, 449-464. http://dx.doi.org/10.1177/1362361311422530

Winner, E. (1979). New Names for Old Things: The Emergence of Metaphoric Language. Journal of Child Language, 6 , 469-491.

Winner, E. (1988). The Point of the Words. Harvard: Harvard University Press.

Winner, E., Rosentiel, A. K., \& Gardner, H. (1976). The Development of Metaphoric Understanding. Developmental Psychology, 12, 289-297. http://dx.doi.org/10.1037/0012-1649.12.4.289 
Scientific Research Publishing (SCIRP) is one of the largest Open Access journal publishers. It is currently publishing more than 200 open access, online, peer-reviewed journals covering a wide range of academic disciplines. SCIRP serves the worldwide academic communities and contributes to the progress and application of science with its publication.

Other selected journals from SCIRP are listed as below. Submit your manuscript to us via either submit@scirp.org or Online Submission Portal.
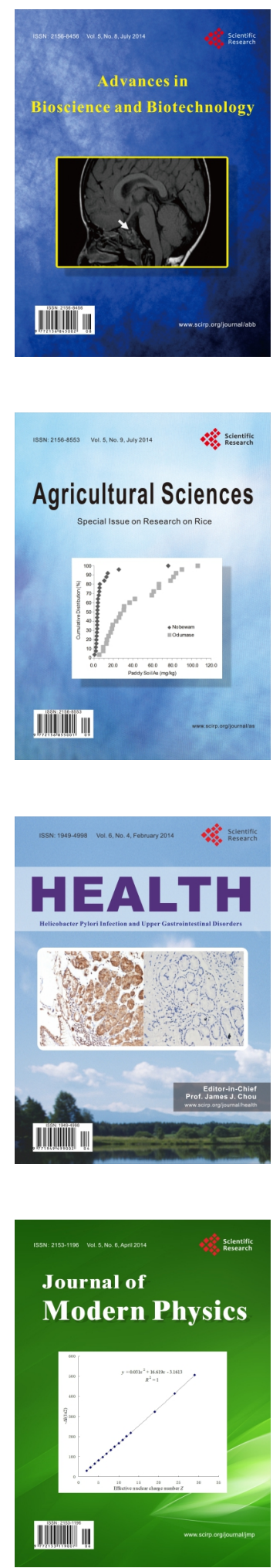
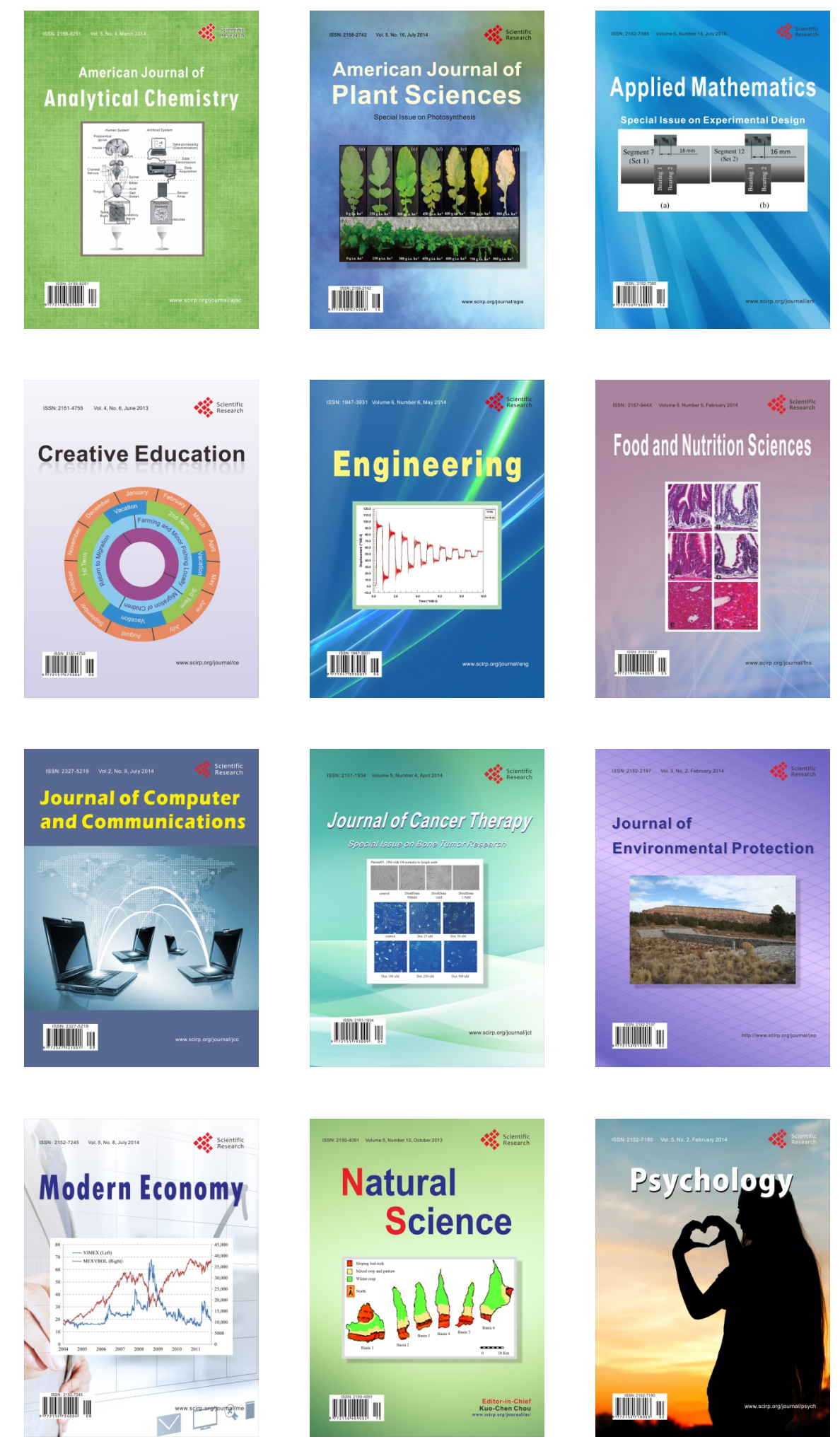